\title{
Buried lumen-apposing metal stent (LAMS) following endoscopic ultrasound-guided gallbladder drainage: the LAMS-in-LAMS rescue treatment
}

A 70-year-old woman with jaundice who had been diagnosed with unresectable malignant distal biliary stricture underwent endoscopic ultrasound (EUS)-guided gallbladder drainage following failed endoscopic retrograde cholangiopancreatography (ERCP). EUS-guided bile duct drainage was impractical because of the presence of an intervening vessel, and an EUS-guided cholecystogastrostomy was created with placement of an $8 \times 8$-mm lumen-apposing metal stent (LAMS) [1].

After 1 month, the patient complained of a recurrence of her jaundice and was scheduled for follow-up endoscopy. This revealed that the proximal flange of the stent was completely buried in the gastric wall (> Fig.1). A linear echoendoscope was then used, and a bending cannula (SwingTip; Olympus) was smoothly inserted through the fistula into the buried LAMS under combined fluoroscopic guidance. Injection of contrast medium revealed a distended gallbladder and slightly dilated intrahepatic biliary tree with no contrast leakage, confirming that the distal flange was still in the correct place ( $\triangleright$ Fig. 2 ).

A 0.035-inch guidewire was then passed through the cannula and coiled within the gallbladder. The delivery catheter of a 10×10-mm electrocautery-tipped LAMS (AXIOS-EC; Boston Scientific) was advanced over the wire into the gallbladder without energizing the device ( $\triangleright$ Video 1). The distal flange of the second LAMS was deployed in the gallbladder beyond the distal flange of the buried LAMS under fluoroscopic guidance. Slight traction was applied on the endoscope-stent coupled system, which allowed the proximal flange of the second LAMS to be deployed in the gastric cavity under endoscopic vision (- Fig.3). A through-the-LAMS-in-LAMS cholangiogram confirmed that the stent was correctly in place and that there was no con-
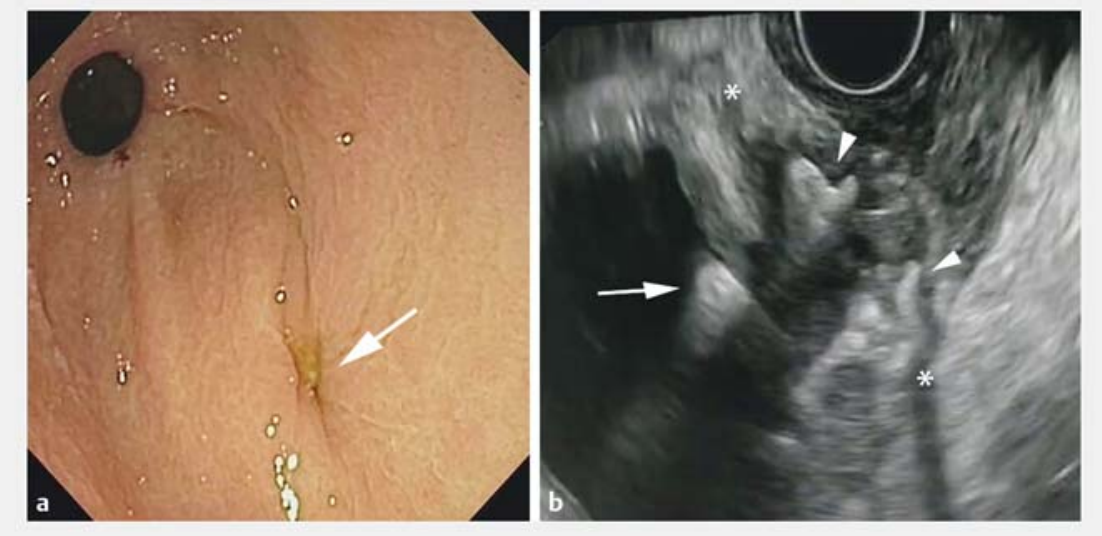

- Fig. 1 The buried stent is seen in the wall of the gastric antrum: a on endoscopic view, showing the proximal flange of the lumen-apposing metal stent completely buried in the gastric wall with a 2-mm fistulous orifice visible on the covering tissue overgrowth (arrow); b on endoscopic ultrasound view, showing the proximal flange (arrowheads) within the gastric wall; a clearly visible hypoechoic gastric muscular layer $\left({ }^{*}\right)$; and the distal flange in place in the gallbladder (arrow).
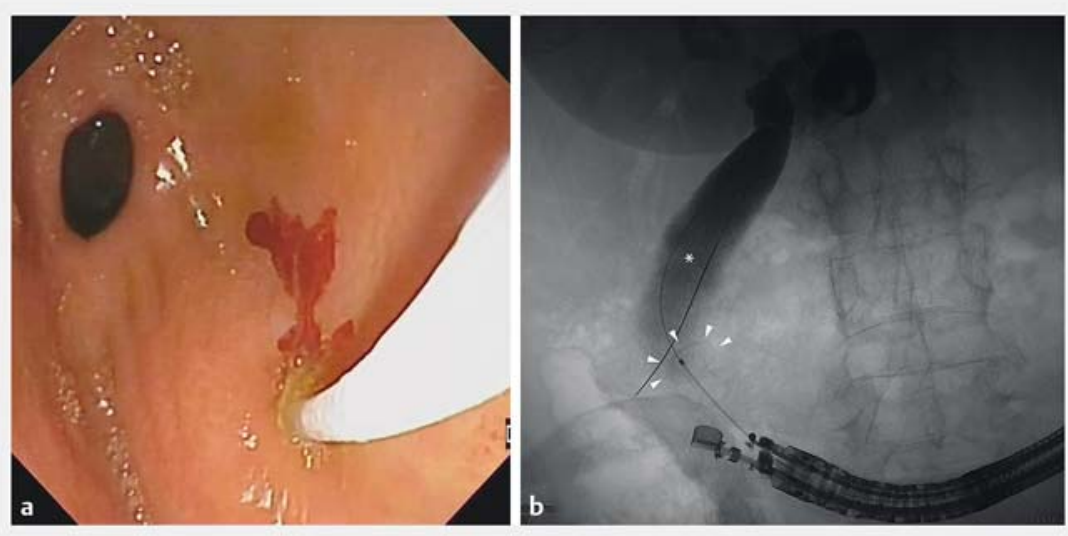

Fig. 2 Images following injection of contrast through the buried lumen-apposing metal stent (LAMS) showing: a on endoscopic view, the cannulation of the fistulous orifice; $\mathbf{b}$ on fluoroscopic view, the distended gallbladder $\left({ }^{*}\right)$; the guidewire coiled inside the gallbladder; and the distal flange of the LAMS still in place (arrowheads).

trast leakage. The post-procedure course was uneventful.

A buried LAMS is a rare complication, previously reported for various indications and managed, when possible, by endoscopic stent removal [2 -4]. In fact, stent removal is not only a technically demand- ing procedure but also, in the setting of biliary drainage, it increases the risk of bile leakage and subsequent peritonitis. The above-described LAMS-in-LAMS technique allows the endoscopist to recreate a safe drainage conduit without the need to remove the buried stent. 


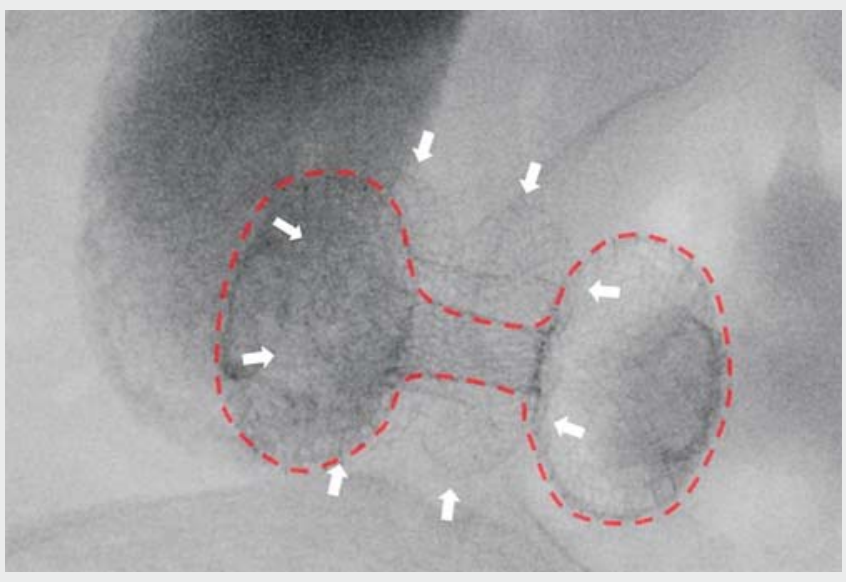

$\checkmark$ Video 1 Video showing a salvage procedure for a buried lumen-apposing metal stent (LAMS) after an endoscopic ultrasound-guided gallbladder drainage: the LAMS-in-LAMS technique. The second LAMS (red dashed line) has both larger flanges and a longer body than the first LAMS (arrows). This ensures a perfect fit for the two coaxial stents.

Endoscopy_UCTN_Code_CPL_1AL_2AD

\section{Competing interests}

None

The authors

\section{Dario Ligresti', Fabio Cipolletta', Michele} Amata ${ }^{1}$, Marta Cimavilla², Mario Traina', llaria Tarantino ${ }^{1}$

1 Endoscopy Service, Department of Diagnostic and Therapeutic Services, IRCCSISMETT (Istituto Mediterraneo per i Trapianti e Terapie ad alta specializzazione), Palermo, Italy

2 Gastroenterology Department, Hospital Universitario Rio Hortega, Valladolid, Spain

\section{Corresponding author}

\section{Dario Ligresti, MD}

Endoscopy Service, Department of Diagnostic and Therapeutic Services, IRCCS ISMETT - UPMC, Via E. Tricomi 5, 90127

Palermo, Italy

Fax: +39-091-2192400

dligresti@ismett.edu

\section{References}

[1] Imai H, Kitano M, Omoto S et al. EUS-guided gallbladder drainage for rescue treatment of malignant distal biliary obstruction after unsuccessful ERCP. Gastrointest Endosc 2016; 84: 147 - 151

[2] Irani S, Kozarek RA. The buried lumenapposing metal stent: Is this a stent problem, a location problem, or both? VideoGIE 2016; 1: 25-26

[3] Seerden TC, Vleggaar FP. Endoscopic removal of buried lumen-apposing metal stents used for cystogastrostomy and cholecystogastrostomy. Endoscopy 2016; 48: E179

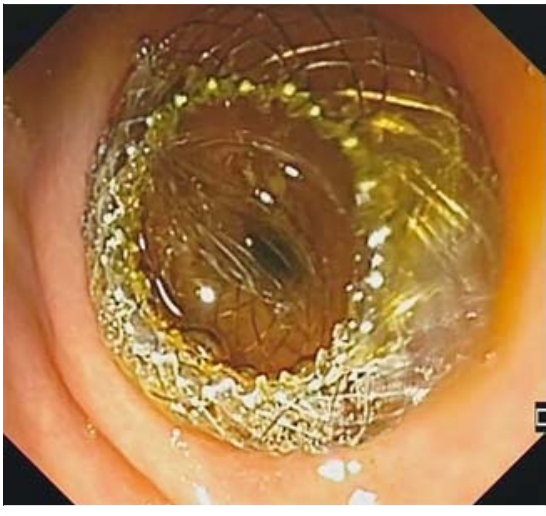

- Fig. 3 Endoscopic view showing the proximal flange of the second lumen-apposing metal stent correctly deployed in the gastric antrum.

[4] Fabbri C, Luigiano C, Marsico M et al. A rare adverse event resulting from the use of a lumen-apposing metal stent for drainage of a pancreatic fluid collection: "the buried stent”. Gastrointest Endosc 2015; 82: 585 587

\section{Bibliography}

DOI https://doi.org/10.1055/a-0624-2050

Published online: 12.6 .2018

Endoscopy 2018; 50: 822-823

(c) Georg Thieme Verlag KG

Stuttgart · New York

ISSN 0013-726X

\section{ENDOSCOPY E-VIDEOS}

https:|/eref.thieme.de/e-videos

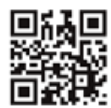

Endoscopy E-Videos is a free access online section, reporting on interesting cases and new

techniques in gastroenterological endoscopy. All papers include a high quality video and all contributions are freely accessible online.

This section has its own submission website at

https://mc.manuscriptcentral.com/e-videos 